\title{
Therapeutic potentials of resveratrol in combination with radiotherapy and chemotherapy during glioblastoma treatment: a mechanistic review
}

\author{
AmirAhmad Arabzadeh ${ }^{1}$, Tohid Mortezazadeh², Tayebeh Aryafar ${ }^{3}$, Esmaeil Gharepapagh4, \\ Mehrsa Majdaeen ${ }^{5^{*}}$ and Bagher Farhood ${ }^{6^{*}}$ (D)
}

\begin{abstract}
Glioblastoma, WHO grade IV astrocytoma, is the most aggressive type of brain tumors. These cancerous cells have a rapid growth rate, tendency to penetrate vital brain structures, molecular heterogeneity, etc. and this cancer is associated with a poor prognosis and low survival rate. Due to the resistance of glioblastoma cells to conventional therapeutic modalities (such as radiation therapy and chemotherapy) as well as the adverse effects of these modalities, the researchers have attempted to discover an appropriate alternative or adjuvant treatment for glioblastoma. Resveratrol, as an herbal and natural polyphenolic compound, has anti-tumoral property and has shown to be effective in GBM treatment. Resveratrol exerts its anti-tumoral effect through various mechanisms such as regulation of cell cycle progression and cell proliferation, autophagy, oxidant system, apoptosis pathways, and so on. Resveratrol in combination with radiation therapy and chemotherapy has also been used. In the present study, we summarized the current findings on therapeutic potentials of resveratrol in glioblastoma radiotherapy and chemotherapy.
\end{abstract}

Keywords: Resveratrol, Glioblastoma, Radiation therapy, Chemotherapy

\section{Introduction}

Gliomas arise from glia cells (including oligodendrocytes, astrocytes, ependymal cells) or cancer stem cells and are categorized histologically in accordance with the similarity to their putative cell of origin [1]. They are different in terms of aggressiveness from benign to highly malignant which are graded from I to IV by the World Health Organization (WHO) $[2,3]$. The most frequent of these fatal tumors in adults is WHO grade IV astrocytoma or glioblastoma (or glioblastoma multiform (GBM)) which

\footnotetext{
*Correspondence: Mehrsa.majdaeen@yahoo.com; farhood-b@kaums.ac.ir

${ }^{5}$ Department of Radiotherapy and Oncology, Razi Hospital, Guilan University of Medical Sciences, Rasht, Iran

${ }^{6}$ Department of Medical Physics and Radiology, Faculty of Paramedical Sciences, Kashan University of Medical Sciences, Kashan, Iran

Full list of author information is available at the end of the article
}

occurs in brain or spinal cord and accounts for $50 \%$ of diffuse gliomas $[4,5]$. The standard treatment modality for GBM is complete surgical resection followed by radiation therapy and chemotherapy. Moreover, a number of efforts have been made to develop new therapeutic modalities. Despite such efforts, these treatment modalities do not dramatically improve clinical outcome of GBM patients $[3,5,6]$. According to a report by Jacksonet al. [2], rapid progression, resistance to treatment, and inexorable recurrence of GBM can be attributed to some factors such as its rapid growth rate, its tendency to penetrate vital brain structures, its molecular heterogeneity, problems in obtaining high concentrations of chemotherapeutic drugs in the central nervous system, etc. It has also been reported that dysregulation of cellular signaling pathways (such as hyperactivation of PI3 original author(s) and the source, provide a link to the Creative Commons licence, and indicate if changes were made. The images or other third party material in this article are included in the article's Creative Commons licence, unless indicated otherwise in a credit line to the material. If material is not included in the article's Creative Commons licence and your intended use is not permitted by statutory regulation or exceeds the permitted use, you will need to obtain permission directly from the copyright holder. To view a copy of this licence, visit http://creativecommons.org/licenses/by/4.0/. The Creative Commons Public Domain Dedication waiver (http://creativeco mmons.org/publicdomain/zero/1.0/) applies to the data made available in this article, unless otherwise stated in a credit line to the data. 
kinase pathway) and genetic mutations (such as mutation in retinoblastoma and p53 genes) can play critical roles in GBM ignition, invasion and progression [7-9].

The use of radiation therapy and chemotherapy can also damage the normal tissues severely; as it may stop the course of cancer treatment due to acute reactions [10]. In other words, these two treatment modalities can be considered as double-edged swords; as the use of these treatments may induce second cancers and adverse effects, negatively affecting patients' quality of life. In this regard, management of early and late complications arisen from cancer treatment without a negative effect on cancer response is one of the most important goals in radiation therapy and chemotherapy $[11,12]$. Therefore, the introduction and development of radio/chemotherapeutic modifiers (as radio/chemoprotectors and radio/ chemosensitizers (can improve therapeutic efficiencies of chemotherapy and radiotherapy [13].

During past decades, tendency to use herbal and natural compounds or their derivatives (with less toxicities) have attracted much attention for various therapeutic purposes, especially cancer treatment. Resveratrol (3,5,4'-trihydroxy-trans-stilbene) is a herbal and natural polyphenolic compound that can be found in grapes, red wine, peanuts, soy, etc. [14-16]. The molecular structure of resveratrol is shown in Fig. 1. This herbal agent has some abilities to kill cancerous cells and amplify tumor response to therapeutic modalities such as radiotherapy and chemotherapy [17]. Interesting properties of resveratrol as a potential anti-oxidant agent have been resulted to its use in other different health benefits, such as neuroprotective and radioprotective effects [18]. Other biological activities of resveratrol such as cardioprotective, chemopreventive, anti-inflammatory, proapoptotic, and anti-proliferative properties have also been reported [15, $16]$.

Despite the remarkable beneficial effects of resveratrol, some studies have failed to reflect these properties which

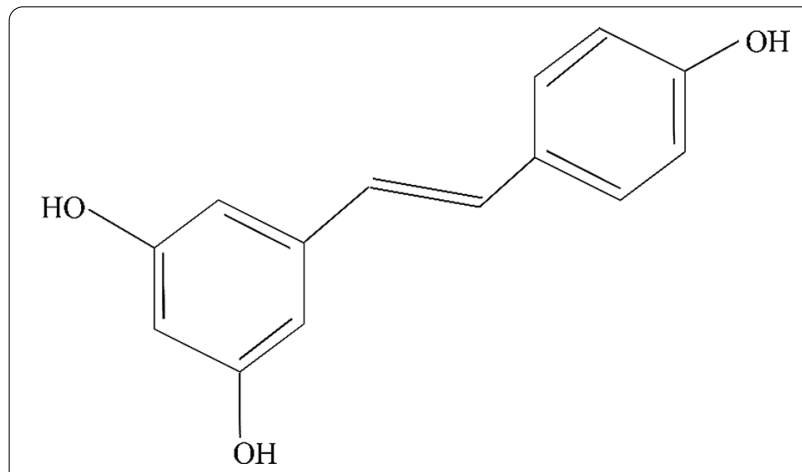

Fig. 1 Chemical structure of resveratrol it may be due to its high absorption but low bioavailability $[19,20]$. Moreover, the use of resveratrol can be compromised because of its hydrophilicity when apply in lipophilic systems [21]; nevertheless, this drawback could be overcome by structural modification [22]. In this regard, some researchers have developed novel resveratrol derivatives, such as pterostilbene [23, 24], trimethoxystilbene $[25,26]$, hydroxystilbene $[27,28]$, dihydroxystilbene [29, 30], bridged stilbenes [31], etc. Compared to resveratrol, modifying some substitutions can improve their bioavailability and biological activities.

The use of nanotechnological strategies can improve the bioavailability and efficacy of resveratrol and its analogues. In this regard, some studies have been investigated the efficacy of resveratrol delivery systems on treatment of many tumors [32-35].

The present review aims to summarize current studies on therapeutic potentials of resveratrol in GBM radiotherapy and chemotherapy. It is also tried to present the resveratrol roles and molecular mechanisms involved in GBM radiotherapy and chemotherapy. Furthermore, the findings obtained from derivatives/analogues and delivery systems of resveratrol in GBM treatment have been addressed.

\section{Role of resveratrol in glioblastoma treatment}

Products derived from nature have been one of the most main and considerable sources in drug discovery and development [36-38]. For many years, the use of natural products and/or natural herbal formulations has been of interest to humans for the preservation of health, improvement of physical and mental health, and prevention of diseases. Many studies have also reported that some natural products in combination with radiotherapy and chemotherapy can have radio/chemoprotective and/ or synergistic effects in terms of alleviating cancer radiotherapy/chemotherapy associated complications and increasing the therapeutic efficacy [14, 39]. Moreover, some of them can penetrate blood brain barrier (BBB) which this property is one of the principal consideration for development of drugs for central nervous system (CNS) $[40,41]$.

Resveratrol is a natural pharmaceutical compound which has a broad range of biological activities such as anti-fungal, anti-viral, anti-inflammatory, anti-oxidant, and anti-aging effects [42-46]. The biological activities of this natural polyphenol are mainly attributed to its unique structure feature with multiple phenolic hydroxyl groups; as polyphenol components are able to scavenge free radicals to produce more stable molecules with low toxicity than the original radicals [47]. It has also been reported that resveratrol can prevent the tumor initiation, promotion and progression [48]; for example, its 
anti-tumoral activity has been assessed in many tumor types, such as colorectal, prostate, lung, liver, breast cancers, etc. [49-52]. Furthermore, resveratrol can cross the BBB successfully and hence, it may be used as an efficient therapeutic or protective agent against CNS-related injuries/disorders and tumors, including global cerebral ischemic injury [53], Alzheimer's [54-56], Parkinson [57, $58]$ and GBM $[59,60]$.

Some studies have also showed that resveratrol, as a radio/chemosensitizer agent, can enhance the therapeutic efficacy of radiotherapy/chemotherapeutic drugs against glioblastoma cells which are discussed the following (Table 1).

\section{Therapeutic potentials of resveratrol in glioblastoma radiotherapy}

Standard treatment for newly diagnosed GBM patients is complete surgical resection followed by adjuvant chemoradiation therapy (CRT) [6, 61]. Conventional radiotherapy protocol used in these patients is as follows: total dose of 59.4 to $60 \mathrm{~Gy}$, dose per fraction of 1.8 or $2.0 \mathrm{~Gy}$, five fractions per week and treatment period of 6 to 7 weeks [62]. In this regard, the use of resveratrol in combination with radiotherapy can increase the therapeutic efficacy (synergistic effects) [63, 64].

One of the reasons for radioresistance of tumoral cells is the upregulation of transcription factors such as signal-transducer-and-activator-of-transcriptions (STATs) after exposure to radiation [12]. These enzymes are transcription factors for cytokine signaling which are constitutively activated in some tumor types such as prostate, breast, brain cancers, nasopharyngeal carcinoma, leukemia, etc. [65-68]. It has been proposed that the targeting of STATs in combination with radiation therapy can be considered as a strategy for overcoming tumor resistance. STAT3, as one of the subfamilies, contributes in modulation of angiogenesis, suppression of apoptosis, regulation of cell cycle progression and metastasis through stimulation of VEGF, MMP-2, MMP-9 and IAP-1 [12, 69]. In a study by Yang et al. [70], the therapeutic effect of resveratrol on GBM-derived radioresistant tumor initiating cells was investigated. In their study, the cells in control and irradiated groups were categorized; as the cells of irradiated groups were exposed to various radiation dose values of $2,4,6,8$, and 10 Gy by a ${ }^{60} \mathrm{Co}$ unit. Their findings revealed that primary GBM-CD133 tumor initiating cells increased protein levels of phosphorylated STAT3 as well as showed high tumorigenic and radiochemoresistant properties. Moreover, they stated that treatment of GBMCD133 cells with $100 \mu \mathrm{M}$ resveratrol increased radiosensitivity and induced apoptosis by suppressing STAT3 signaling. Resveratrol also facilitated the differentiation of $\mathrm{GBM}_{-\mathrm{CD}} 133^{+}$into GBM-CD133- and prevented the stemness gene signatures of GBM-CD $133^{+}$. In addition, the xenotransplant experiments showed that the use of resveratrol can significantly improve the survival rate and synergistically increase the radiosensitivity of GBM-tumor initiating cells exposed to radiation [70]. It is notable that one of the main contributors to radioresistance are cancer stem cells (CSCs). These cells are also responsible for cancer progression and recurrence of gliomas after conventional treatment modalities [71-75]. It has also been reported that radioresistance is resulted from brain tumor-derived CD $133^{+}$cells that possess CSC capabilities [76-79].

The role of gap junction intercellular communication (GJIC) in the modification of growth and cell death has been proven. The changes in GJIC (including loss of homologous and/or heterologous) happens during the promotion/progression stages of carcinogenic process [80]; as the majority of cancerous cells lack GJIC [81]. Furthermore, additional epigenetic or genetic modifications, which stably inhibit GJIC, can lead to grow the cell without inhibition; hence, it becomes genomically unstable and obtains phenotypes needed for invasion and metastasis. In a study by Leone e al. [82], the regulation of cell cycle progression induced by resveratrol and association of this regulation with gap junction expression in human glioma U87 cells were investigated. They also evaluated the ability of this polyphenol to enhance radiosensitivity of these cancerous cells. In that study, the cells were treated with various dose values of resveratrol $(0$, $20,40,80,160,320$, and $640 \mu \mathrm{M})$. To assess the combined therapeutic efficacy, the cells were treated with $20 \mathrm{mM}$ resveratrol for 1 day and were then irradiated with 5 Gy $\mathrm{X}$-rays. Their results showed that resveratrol significantly increased the fraction of cancerous cells in $\mathrm{S}$ phase of cell cycle in a dose-dependent manner (starting from $20 \mu \mathrm{M}$ ). Also, treatment with resveratrol resulted in a significantly higher fraction of cancerous cells in S phase compared to untreated cells (control group), with a concomitant significant decrease in the fraction of cancerous cells in G1 phase. These findings revealed a time-dependent manner and percentage of cancerous cells both in the S and G1 phase was comparable to that of control cells after'2-day resveratrol treatment. Additionally, 24-48 h after the $\mathrm{X}$-ray treatment of cancerous cells, a significant increase of cancerous cells in the G2 phase compared to non-irradiated cells was observed, with a concomitant significant reduction of cancerous cells in G1 phase. The results of combined treatment (resveratrol $+\mathrm{X}$-rays) demonstrated a significantly increase of cancerous cells in the $S$ phase after irradiation, with a concomitant significant decrease in G1 phase cells (in a time-dependent manner). Compared to resveratrol or X-rays alone, the combined treatment showed a significant increase of S phase cells (after 


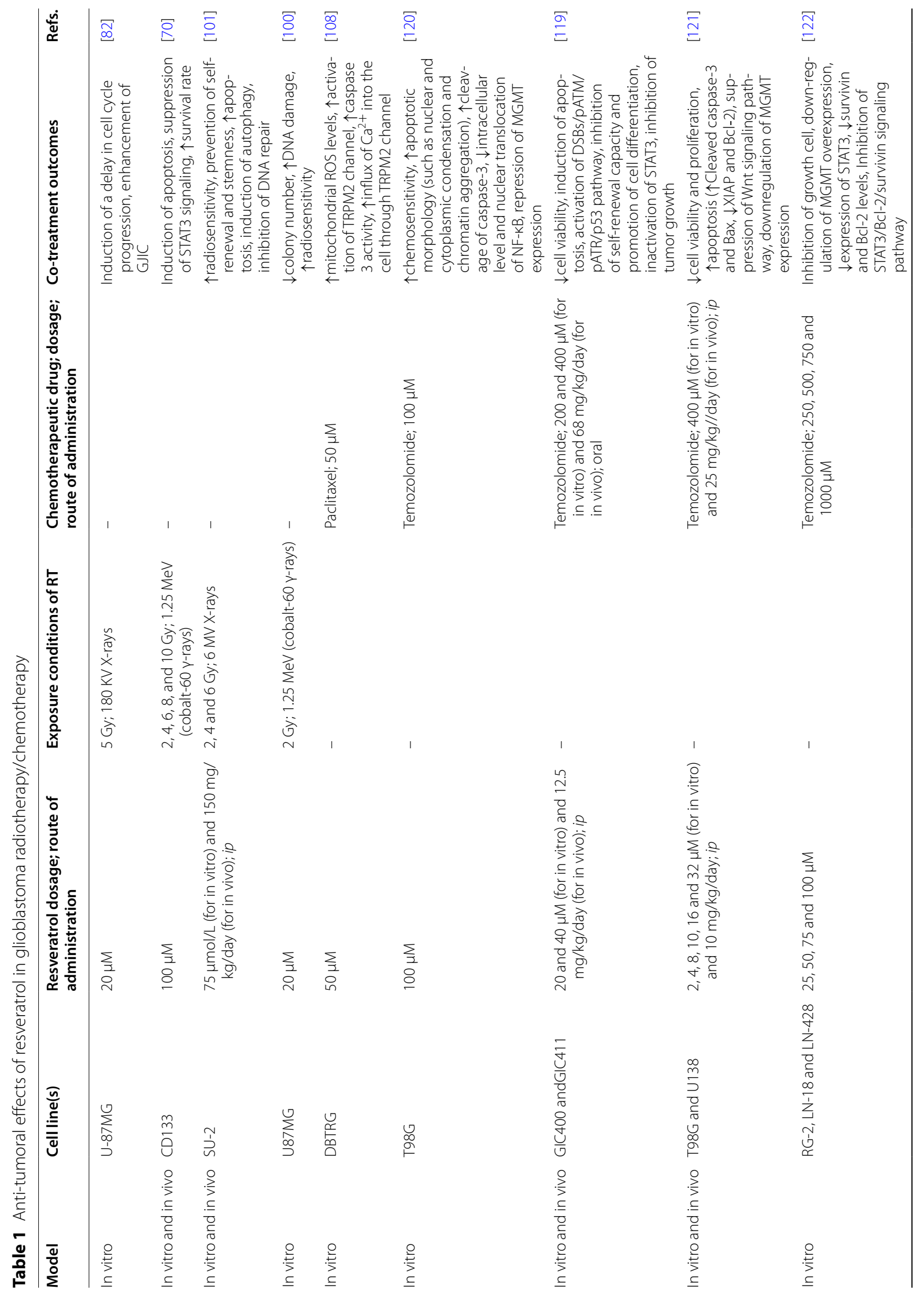




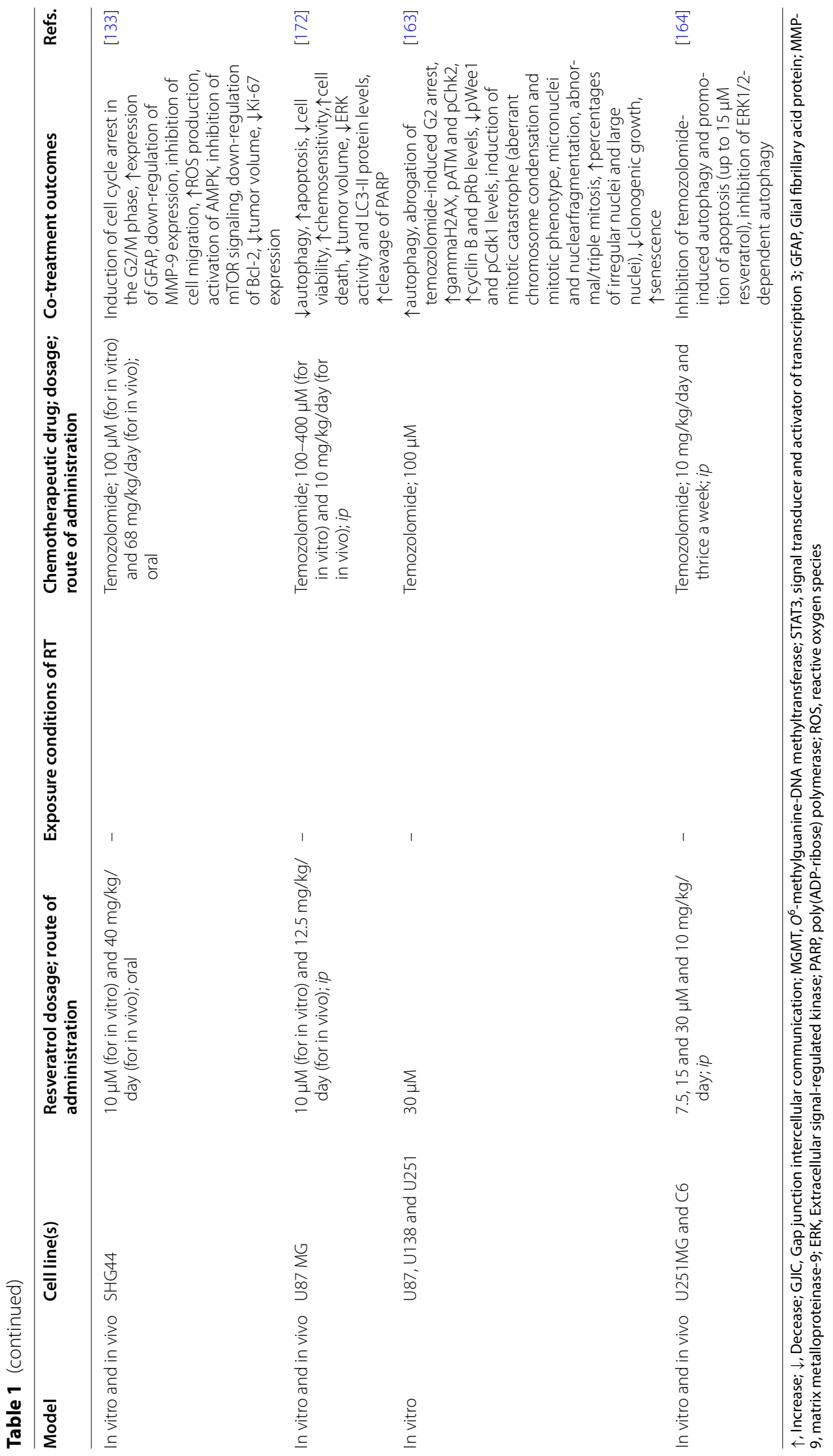


28 and $30 \mathrm{~h}$ ), with a concomitant decrease of G1 phase cells. Two days after irradiation, there was a significant increase in the fraction of G2 phase cells for combined treatment in comparison to single treatment. In conclusion, they stated that resveratrol can induce a delay in cell cycle progression and it is also capable of enhancement of GJIC, both alone and in combination with X-rays [82].

Hypoxia is known as a common characteristic of all solid malignancies [83-86] and it adjusts wide aspects of tumor biology, consisting of cellular proliferation, angiogenesis, invasion and metastasis $[87,88]$. It has been shown that hypoxia is strongly related with poor prognosis [89-91] and it is considered as a leading cause of therapy resistance [92, 93]. Hypoxia-inducible factors (HIFs), including two $\alpha$ and $\beta$ subunits, are mediators of hypoxia and responsible for monitoring cellular responses to oxygen levels [83, 94]. Among HIFs, HIF- $1 \alpha$ and HIF- $2 \alpha$ have critical roles in solid malignancies [83]; as these two factors adjust apoptosis, inhibit cellular differentiation, and activate DNA repairing enzymes, support formation of blood vessels, all of which are associated to treatment resistance [95]. Hypoxic tumor cells are also radioresistant [96] and these cells represent a two- to three-fold increase in radioresistance [97]. Hypoxia is a common characteristic in gliomas and decreases the sensitivity of cancerous cells to radiotherapy [98]; hence, inhibition of HIFs pathway may reduce radioresistance of glioma cells [99]. In this regard, it has been reported that resveratrol can inhibit HIF-1 $\alpha$ expression in the hypoxia condition. Khoei et al. [100] investigated effect of resveratrol on radiosensitivity of iododeoxyuridine (IUdR), a halogenated pyrimidines analogue which is one of the most effective non-hypoxic radiosensitizers, in U87MG glioblastoma cell line. The cells were treated with $20 \mu \mathrm{M}$ resveratrol and/or $1 \mu \mathrm{M} \mathrm{IUdR}$, and were then exposed to $2 \mathrm{~Gy}$ radiation dose (by ${ }^{60} \mathrm{Co}$ unit). Their findings revealed that resveratrol significantly decreased colony number and increased the DNA damages of GBM cells treated with IUdR in combination with radiotherapy. In conclusion, they stated that use of resveratrol (as HIF-1 $\alpha$ inhibitor) in combination with IUdR (as radiosensitizer) can enhance the radiosensitization of U87MG glioblastoma cells [100].

In addition to the above-mentioned mechanisms, resveratrol can induce senescence and autophagy as well as attenuate the stemness of CSCs, leading to radiosensitization of cancer cells [101, 102]. Wang et al. [101] evaluated the therapeutic efficacy of resveratrol in combination with radiotherapy against radioresistant SU-2 glioma stem cells in both in vitro and invivo models. In that study, the cells and mice were treated with resveratrol in dose values of $75 \mu \mathrm{mol} / \mathrm{L}$ and $150 \mathrm{mg} / \mathrm{kg}$, respectively and were then exposed to 0-6 Gy radiation dose values generated from a $6 \mathrm{MV} \mathrm{X}$-ray linear accelerator. They represented that resveratrol has the ability to significantly increase the radiosensitivity of cancerous cells in both in vitro and nude mouse models which it can be attributed to its synergistic anti-cancer effects, including prevention of self-renewal and stemness, increase of apoptosis, induction of autophagy, and inhibition of DNA repair [101]. Self-renewal is a key property of stem cells and this ability of CSCs is necessary for tumorigenesis and tumor development [103]. CSCs also present stemness potential and this shows that proliferative cancer cells are continuously renewed by asymmetric division of CSCs [104].

\section{Therapeutic potentials of resveratrol in glioblastoma chemotherapy}

A range from common chemotherapeutic agents are used for GBM treatment, such as temozolomide, doxorubicin, paclitaxel, etc. Some studies showed that resveratrol, as a chemosensitizer agent, can enhance the therapeutic efficacy of chemotherapeutic drugs through several mechanisms, which are discussed the below.

Oxidative stress conditions occur following the chemotherapy drug administration. The generated reactive oxygen species (ROS) can induce DNA damage either directly or indirectly, resulting in cancerous cell death [105]. It has been reported that resveratrol can increase ROS level in cancerous cells [106-108]. For instance, the interaction of resveratrol with the mitochondria of cancerous cells can induce an imbalance in cellular antioxidant activities, thereby a remarkable increase in the levels of both intracellular ROS and lipid peroxides [107]. Furthermore, resveratrol can inhibit oxidation-reduction (redox) system in cancerous cells [107]. It is notable that redox systems normally prevent cell oxidative damage; nevertheless, the cellular redox mechanisms in brain tumors are highly impaired which lead to the stimulation of survival cell pathways, thereby facilitating tumor growth and resistance [105]. Moreover, combined therapy using the resveratrol and chemotherapy agents showed synergistic effects against the cancerous cells in terms of ROS levels and redox activity $[107,108]$. Öztürk et al. [108] investigated therapeutic efficacies of resveratrol $(50 \mu \mathrm{M})$, paclitaxel $(50 \mu \mathrm{M})$, and resveratrol plus paclitaxel on DBTRG glioblastoma cells. Their results showed that mitochondrial ROS levels significantly increased in these cancerous cells following treatment with paclitaxel and resveratrol. The mitochondrial ROS level of cells also increased further following combined treatment of paclitaxel plus resveratrol (synergistic effect). They also stated that synergic interactions of resveratrol on paclitaxel-induced oxidative stress can stimulate activation of the TRPM2 channel in the glioblastoma 
cells; as these changes contribute to the cancerous cell death by increment of the influx of $\mathrm{Ca}^{2+}$ into the cell through the channel [108].

Evasion of apoptosis is one of the features of most malignant cells, because defects in regulators of this physiological process invariably accompany tumorigenesis and maintain malignant progression [109]. Some chemotherapeutic agents induce apoptosis in cancerous cells [110]. It has also been reported that the resveratrol is able to induce apoptosis in different cancerous cells, such as glioma [111], prostate [112], breast [113], head and neck [114], ovarian [115] cancer cells. The apoptotic activity of resveratrol is related to induce ROS production, caspases activation, mitochondrial membrane permeability, p53 and BAX activation, etc. [106, 108, 116-118]. Furthermore, some studies have reported that the use of resveratrol can enhance chemotherapy-induced apoptosis in glioblastoma cell lines. The mechanisms would be either increased expression levels of apoptotic factors such as p53, BAX and caspase 3 or decreased expression levels of anti-apoptotic factors such as NF- $\mathrm{kB}$ and BCL-2 [119-122]. Li et al. reported that temozolomide-induced apoptosis in glioblastomainitiating cells is enhanced by resveratrol through DNA double-stranded breaks (DSBs)/pATM/pATR/p53 pathway activation [119]. Huang et al. [120] stated that T98G glioblastoma cells receiving combination treatment of resveratrol and temozolomide had an increased apoptotic morphology, such as nuclear and cytoplasmic condensation and chromatin aggregation. Their other findings showed a significant increment in cleavage of caspase- 3 and reduction in intracellular level and nuclear translocation of NF- $\mathrm{KB}$ in the cancerous cells treated with resveratrol and temozolomide than those treated with temozolomide alone [120]. Yang et al. reported that resveratrol could sensitize temozolomide-induced glioma cell apoptosis by suppressing Wnt signaling pathway activation and downregulating O-6-methylguanine-DNA methyltransferase expression [121].

Many studies have reported that resveratrol can regulate cell cycle progression and cell proliferation in different cancers, such as pancreatic cancer [123], breast cancer [124], melanoma [125], lung cancer [126], glioblastoma [59], and so on. Resveratrol exerts its tumor-suppressive effect through inhibition of NF- $\kappa B$, mitogen-activated protein kinases (MAPKs), cyclooxygenases, metabolism of prostaglandins and also induction of apoptotic factors $[12,127,128]$. This chemosensitizer agent can also enhance AMPK expression (as a stimulator of p53) and prevent Akt expression (as a cancer proliferation gene) [63]. Inhibition of mTOR pathway may suppress Akt pathway [129]. Moreover, resveratrol may stop cell cycle progression through preventing DNA replication [130, 131]. It has also been reported that resveratrol via stimulation of SIRT1 increases the regulation of cyclin D1 which leads to inhibition of cancerous cell proliferation [132]. Furthermore, it has been reported that resveratrol can enhance cancer cell suppression induced by chemotherapy agents. Yuan et al. [133] stated combined treatment of resveratrol and temozolomide against U251 glioma cells significantly results in G2/M cell cycle arrest. They also reported that the chemotherapy drug in combination with resveratrol considerably increased ROS production which activated AMPK. Then, activated AMPK prevented mTOR signaling and downregulated BCL-2. Moreover, results of in vivo (an orthotopic xenograft model of glioblastoma) showed that combination treatment significantly decreased the volume tumor. Finally, they stated that resveratrol can enhance temozolomide-mediated anti-tumoral effects in glioblastoma through ROS-dependent AMPK-TSCmTOR signaling pathway [133].

CSCs, a small population of cancerous cells, are tumorinitiating cells and include a group of quiescent selfrenewing cell types which pre-exist in primary malignant tumors and localized within the tumor niches bearing enriched functional potential to drive tumor growth, to reconstruct their heterogeneity and to make changes in tumor regenerative capacity $[134,135]$. The different cell surface markers are often applied to identify and enrich CSCs, including CD44, CD24, and CD133 [136]. Glioblastoma stem cells play main roles in the glioblastoma development and therapeutic resistance [76, 137-139]. It has also been reported that there is an association between tumor formation by the glioblastoma stem cells and their peculiar resistance to chemotherapy treatment in comparison with other cell populations of the tumor [140]. The first accepted surface marker for glioblastoma stem cells was CD133 [141] that it allows the subdivision of stem cells into two groups of $\mathrm{CD} 133^{+}$or cancer stem cells and $\mathrm{CD}_{133^{-}}$or non-cancer stem cells [142]. Other markers expressed in glioblastoma stem cells are CD15, CD184, CD44, A2B5, CD90, SOX2, OCT-4, SALL4, NANOG, ALDH1, L1CAM, KLF4, and so on [76, 143-153]. Some studies have reported that resveratrol is able to target glioma glioblastoma stem cells through various molecular pathways involved in self-renewal and several stem cell markers. Song et al. showed that resveratrol could inhibit self-renewal ability of glioma stem cells and cancer stem cell markers (such as Bmil and Sox2) induced by epithelial mesenchymal transition [154]. Sayd et al. reported that increased expression of SIRT2 induced by resveratrol inhibits glioma stem cell proliferation [155]. Clark et al. [59] mentioned that resveratrol significantly inhibited proliferation and invasion of glioblastoma stem cells. This chemosensitizer 
agent also inhibited the sphere-forming ability. They also reported that resveratrol decreases AKT phosphorylation and induces p53 expression and activation. It is noteworthy that AKT and p53 mechanisms involve in growth, survival, and invasion of glioblastoma [59]. Cilibras et al. evaluated effect of resveratrol on glioma stem cells and showed that it is able to inhibit cell proliferation, increase cell mortality, and decrease cell motility. They also reported that resveratrol can modulate Wnt signaling pathway and epithelial mesenchymal transition activators [156]. Li et al. [119] demonstrated the use of resveratrol sensitizes temozolomide-induced apoptosis of glioblastoma-initiating cells through activation of the DSBs/pATM/pATR/p53 pathway. They also mentioned that combined treatment of temozolomide and resveratrol could induce cell differentiation and inhabit self-renewal capacity of glioblastoma-initiating cells via STAT3 inactivation [119]. Figure 2 represents some signaling pathways in cancer (stem) cells that regulate apoptosis, metastasis or angiogenesis following radiotherapy or chemotherapy.

Autophagy, as a physiological cellular process, participates in cell death under different conditions $[157,158]$.
The autophagic process is also associated with various diseases such as cancer [159]. It can decrease cell instability and damage to prevent tumorigenesis; hence, the regulation of autophagic process is of great significance in cancer treatment [160,161]. Aberrant regulation of autophagy has been reported in different diseases and is common in tumors $[159,160]$. For instance, autophagy deficiency can result in aberrant accumulation of p62 (an autophagy adaptor protein and preferred target for autophagy) and activate p62-regulated pathways, such as activation of mTOR and Keap1-Nrf2 pathways which are associated with tumor development [160]. Moreover, some cancer types such as glioblastoma are intrinsically resistant to apoptotic cell death and may be more sensitive autophagy [162]. Autophagy has a dual role in cancers and may result in sensitization or resistance of cancerous cells. This dual role induced by autophagy is remarkably dependent on genetic changes in cancerous cells [12]. The chemotherapeutic agents can induce autophagy in cancerous cells through different mechanisms; however, alteration in autophagic response could be considered as a key mechanism in drug resistance [163-166]. Resveratrol regulates the autophagic process

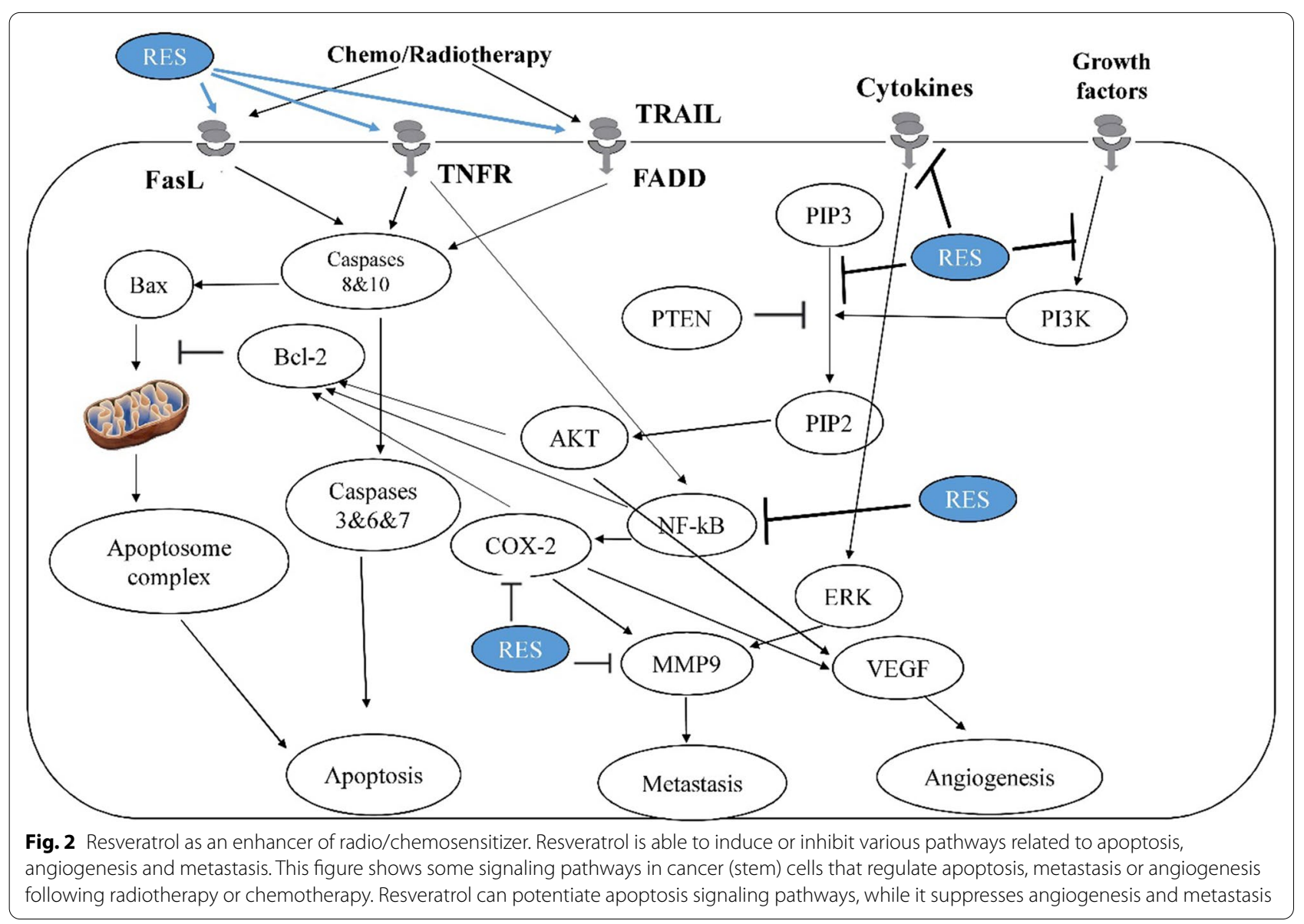


and may affect the response of cancerous cells to therapy [12]. It has also been reported that resveratrol inhibits glioblastoma cell growth and causes the cell death through mechanisms involved in autophagy [167, 168]. Induction of autophagy by resveratrol can happen by several mechanisms, including the acceleration of p62 degradation, suppression of mTOR and Nrf2 activations, induction of apoptosis, activation of p38-MAPK pathway, inhibition of STAT3 activation, and so on [160, 169-171]. Furthermore, the effect of resveratrol on chemotherapyinduced autophagy in glioblastoma cells has been investigated (Fig. 3). Lin et al. [172] reported that temozolomide induced both apoptosis and cytoprotective autophagy in glioma cells via a ROS burst and extracellular signal-regulated kinase (ERK) activation; however, resveratrol suppressed them and resulted in a reduction in autophagy and an increment in apoptosis. Therefore, they suggested that the ROS/ERK pathway can play a critical role in the fate of cancerous cells after temozolomide treatment. Furthermore, an in vivo mouse xenograft study revealed that the combined treatment of temozolomide and resveratrol can decrease ERK activity and LC3-II protein level as well as increase the cleavage of PARP; as these findings represented that resveratrol enhances tumor apoptosis through suppressing the autophagic pathway. In conclusion, they reported that resveratrol sensitizes glioma cells to temozolomide-mediated apoptosis in a synergistic manner via down-regulation of protective autophagy [172]. Zanotto-Filho et al. [164] showed that temozolomide efficacy in glioblastoma treatment improved by inhibition of ERK1/2-dependent autophagy induced by resveratrol. In another study by FilippiChiela et al. [163], it was shown that resveratrol increases autophagy induced by temozolomide in glioblastoma cells, but autophagy did not affect acute cell death.

\section{Resveratrol derivatives/analogues in glioblastoma treatment}

In the current study, the anti-tumoral, radiosensitizer, and chemosensitizer properties of resveratrol were reviewed and it was found that resveratrol, in addition to having anti-tumoral properties alone, can have synergistic effects in combination with radiotherapy and chemotherapy. Despite its remarkable anti-cancer beneficial effects, unfavorable pharmacokinetics/pharmacodynamics profile of resveratrol such as poor bioavailability has restricted its applications. Hence, researchers have synthesized novel derivatives and analogues for this antitumoral agent using various modification strategies to overcome these restrictions and improve anti-tumoral efficacy. The anti-tumoral properties of resveratrol derivatives/analogues have been evaluated in different cancers such as breast cancer [173], ovarian cancer [174], gastric cancer [175], renal carcinoma, lung cancer, colon cancer, prostate cancer [176], glioblastoma [177], etc. The design, synthesis, and anti-tumoral properties of resveratrolbased compounds have recently reviewed by Ahmadi and Ebrahimzadeh [178].

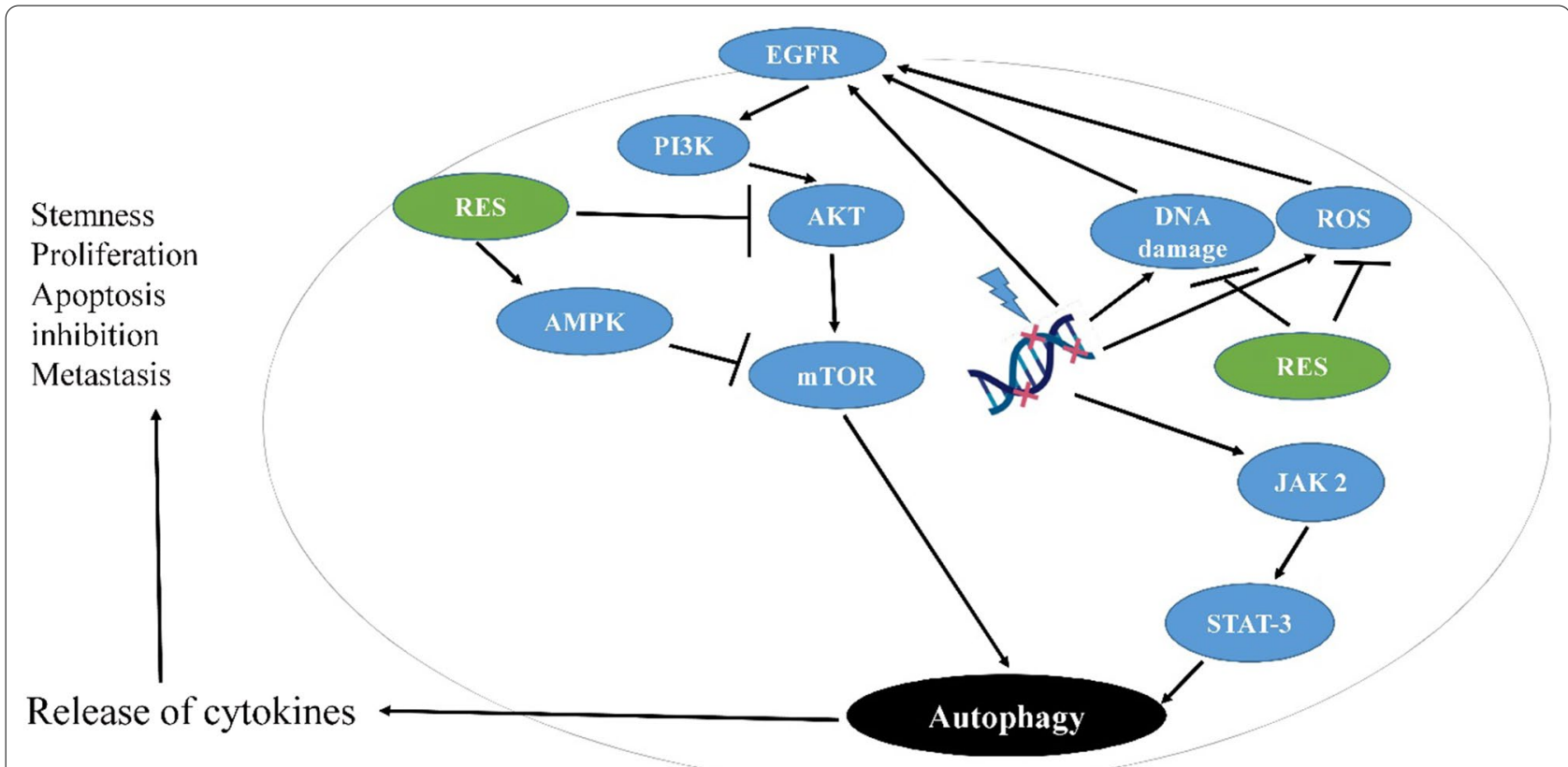

Fig. 3 Schematic mechanisms for anti-tumor effect of resveratrol in glioblastoma through inhibition of autophagy pathways 
In a study by Chelsky et al. [177], anti-tumoral effect of the resveratrol derivative $(E)$-4-(3,5-dimethoxystyryl) phenyl acetate against U251MG glioma cells was investigated. Their findings showed that the use of this resveratrol analog resulted in reduction of colony formation, induction of cell cycle arrest in the G2/M phase, suppression of survivin, Bcl-xL, cyclin D1 and cyclin B1 expression, and induction of cleavage of caspases 3,8 , and 9 and poly(ADP ribose) polymerase. Mechanistically, it was found that treatment of U251MG cells with this resveratrol analog resulted in suppression of STAT3 tyrosine705 phosphorylation and induction of STAT3 serine727 phosphorylation [177]. Zielińska-Przyjemska et al. [179] assessed effects of resveratrol and its analogs (3,5,4'-Trimethoxystilbene (TMS) and pterostilbene) on apoptosis and cell cycle in rat C6 and human T98G glioma cells. Their results showed that resveratrol and pterostilbene administrations increased percentage of the cancerous cells in $\mathrm{S}$ phase, while TMS led to a massive accumulation of cancerous cells at the G2/M phase of the cell cycle. Furthermore, the apoptosis rate in the cancerous cells was most significantly increased by TMS through p53 induction [179]. Majchrzak-Celinska et al. [180] investigated the anti-tumoral effects of resveratrol and its five analogs on T98G glioblastoma cells. They reported that these agents downregulated the expression of genes involved in Wnt/ $\beta$-catenin pathway. Moreover, it was observed that the $4^{\prime}$-methoxy substituted derivatives had higher activity, whereas 3,4,4'-Tri-methoxy-transstilbene was the most potent Wnt/ $\beta$-catenin pathway inhibitor. Furthermore, administration of the compounds did not affect DNA methylation level of MGMT, SFRP1, or RUNX3T, despite moderate alterations in expression levels of epigenetic modifiers DNMT3B and TET1-3 were observed. Importantly, it was found that treatment with 3,4,4'-Trimethoxy-trans-stilbene and 3,4,2',4'-tetramethoxy-trans-stilbene resulted to cycle arrest in the $\mathrm{S}$ phase and induced apoptosis [180].

To the best of our knowledge, no research has been conducted on the radio/chemosensitizer properties of resveratrol derivatives/analogues in glioblastoma treatment. Therefore, it is proposed studies geared towards this direction.

\section{Delivery systems of resveratrol in glioblastoma treatment}

Besides the beneficial effects of resveratrol, several drawbacks such as poor solubility in water, high photosensitivity, and low oxidative stability have limited its application. It has been reported that nanostrategies for delivery of resveratrol can overcome to these limitations. For instance, improved toxicity against cancerous cells was obtained by polymeric and lipid-based nanocarriers.
Or, silica nanoparticles significantly improved the biological activity and loading capacity of resveratrol and gold and silver nanoparticles promoted anti-bacterial and anti-tumoral activities of resveratrol [181].

There are some studies which have evaluated the efficacy of delivery systems of resveratrol in glioblastoma treatment. Shao et al. [182] synthesized resveratrolloaded methoxy poly(ethylene glycol)-poly(caprolactone) (mPEG-PCL) nanoparticles with high encapsulation efficiency, because of its lipophilicity. They also stated that the resveratrol-loaded nanoparticles at lower concentration could cause significantly higher glioma cell death in comparison with equivalent dose of free resveratrol. Moreover, ROS determination showed the significantly lower intracellular ROS levels in resveratrol-treated cancerous cells compared to nanoparticle-treated cancerous cells. Hence, they reported that the differential cytotoxicity between free resveratrol and resveratrol-loaded nanoparticles may be mediated by the difference of intracellular ROS levels [182]. Figueiró et al. [183] investigated the anti-tumoral effect of resveratrol-loaded lipid-core nanocapsules against C6 glioma cells in both in vitro and in vivo models. In vitro, the resveratrol-loaded nanoparticles reduced the viability of cancerous cells to a higher extent than free resveratrol through induction of apoptotic cell death. In vivo, treatment with the nano-complex promoted a remarkable reduction in tumor size and also decreased the incidence of some cancer-associated characteristics (such as intratumoral edema and hemorrhaging) compared to free resveratrol [183]. Guo et al. [184] assessed therapeutic efficacy of transferrin-modified PEG-poly lactic acid (PLA) nanoparticles conjugated with resveratrol against C6 and U87 glioma cells in both in vitro and in vivo models. Their findings showed that in vitro cytotoxicity of nano-complex against the cancerous cells was higher than that of free resveratrol. In comparison with free resveratrol, the nano-complex could significantly reduce tumor volume and accumulate in brain tumor, thereby prolonging the survival of tumor-bearing rats [184]. Jhaveri et al. [185] synthesized resveratrol-loaded PEGylated liposomes and modified the liposome surface with transferrin moieties to make them tumor cell-specific. They reported that the transferrin-modified PEG-PLA nanoparticles conjugated to resveratrol had significantly more cytotoxic and increased apoptosis accompanied by activation of caspases $3 / 7$ in U-87 MG glioblastoma cells compared to free resveratrol or resveratrol-loaded PEGylated liposomes. In addition, their results demonstrated that transferrinmodified PEG-PLA nanoparticles conjugated to resveratrol were more effective than other treatments in inhibition of tumor growth and improvement of survival in tumor-bearing mice [185]. Xu et al. [186] constructed, 
characterized and tested mPEG-PCL nanoparticles coloaded with temozolomide and resveratrol for antitumoral effect against U87 glioma cells in both in vitro and in vivo models. The temozolomide/resveratrolcoloaded nanoparticles induced higher apoptosis in the cancerous cells compared to those treated by the combination of free temozolomide and resveratrol. Moreover, the temozolomide/resveratrol-coloaded nanoparticles led to more effective inhibition of phosphor-Akt, resulting to upregulation of the downstream apoptotic proteins. Furthermore, the in vivo findings demonstrated the superior tumor delaying effect of the temozolomide/resveratrol-coloaded nanoparticles compared to that of free temozolomide and resveratrol combination [186].

However, more studies are required to approve the effectiveness of nano-based delivery systems of resveratrol in glioblastoma treatment. In addition, it is proposed to evaluate the delivery systems of resveratrol in combination with radiotherapy and chemotherapy.

\section{Conclusions}

The standard treatment modality for GBM include surgery, radiation therapy and/or chemotherapy. Nevertheless, these cancerous cells are resistant to radiation therapy and chemotherapy; hence, efficient therapeutic modalities for GBM treatment are still required. Resveratrol, as an anti-tumoral agent, has shown to be effective in GBM treatment and it exerts this property through various mechanisms such as regulation of cell cycle progression and cell proliferation, autophagy, oxidant system, apoptosis pathways, etc. The synergistic effects of resveratrol in combination with radiation therapy (radiosensitizer) and chemotherapy (chemosensitizer) have also been confirmed. Furthermore, the use of derivatives/analogues and delivery systems of resveratrol could improve anti-tumoral efficacy of resveratrol.

\section{Acknowledgements}

Not-applicable.

\section{Authors' contributions}

AAA gave the idea and drafted several part of the manuscript. TM, TA and EG performed the literature search and drafted figures. MM and BF gave the idea, edited the manuscript and supervised the whole study. All authors read and approved the final manuscript.

\section{Funding}

Not-applicable.

\section{Availability of data and materials}

The datasets used and/or analyzed during the current study are available from the corresponding author on reasonable request.

\section{Declarations}

Ethics approval and consent to participate Not-applicable.
Consent for publication

Not-applicable.

\section{Competing interests}

The authors declare no conflict of interest.

\section{Author details}

${ }^{1}$ Department of Surgery, School of Medicine, Ardabil University of Medical Sciences, Ardabil, Iran. ${ }^{2}$ Department of Medical Physics, School of Medicine, Tabriz University of Medical Science, Tabriz, Iran. ${ }^{3}$ Department of Radiation Sciences, Yasuj University of Medical Sciences, Yasuj, Iran. ${ }^{4}$ Medical Radiation Sciences Research Team, Tabriz University of Medical Science, Tabriz, Iran.

${ }^{5}$ Department of Radiotherapy and Oncology, Razi Hospital, Guilan University of Medical Sciences, Rasht, Iran. ${ }^{6}$ Department of Medical Physics and Radiology, Faculty of Paramedical Sciences, Kashan University of Medical Sciences, Kashan, Iran.

Received: 31 May 2021 Accepted: 15 July 2021

Published online: 21 July 2021

References

1. Louis DN, Perry A, Reifenberger G, von Deimling A, Figarella-Branger D, Cavenee WK, et al. The 2016 World Health Organization Classification of tumors of the central nervous system: a summary. Acta Neuropathol. 2016;131(6):803-20.

2. Jackson CM, Choi J, Lim M. Mechanisms of immunotherapy resistance: lessons from glioblastoma. Nat Immunol. 2019;20(9):1100-9.

3. Urso K, Fernández A, Velasco P, Cotrina J, de Andrés B, Sánchez-Gómez P, Hernández-Laín A, Hortelano S, Redondo JM, Cano E. NFATc3 controls tumour growth by regulating proliferation and migration of human astroglioma cells. Sci Rep. 2019;9(1):9361

4. Ostrom QT, Gittleman H, Stetson L, Virk SM, Barnholtz-Sloan JS. In: Current understanding and treatment of gliomas. Vol. 163. Springer: New York, pp. 1-14.

5. Shabaninejad Z, Pourhanifeh MH, Movahedpour A, Mottaghi R, Nickdasti A, Mortezapour E, et al. Therapeutic potentials of curcumin in the treatment of glioblstoma. Eur J Med Chem. 2020;188:112040.

6. Stupp R, Mason WP, van den Bent MJ, Weller M, Fisher B, Taphoorn MJ, et al. Radiotherapy plus concomitant and adjuvant temozolomide for glioblastoma. N Engl J Med. 2005;352(10):987-96.

7. Watanabe K, Tachibana O, Sata K, Yonekawa Y, Kleihues P, Ohgaki H. Overexpression of the EGF receptor and p53 mutations are mutually exclusive in the evolution of primary and secondary glioblastomas. Brain Pathol. 1996;6(3):217-23 (discussion 23-4).

8. Lino MM, Merlo A. PI3Kinase signaling in glioblastoma. J Neurooncol. 2011;103(3):417-27.

9. Poch E, Miñambres R, Mocholí E, Ivorra C, Pérez-Aragó A, Guerri C, et al. $\mathrm{RhoE}$ interferes with $\mathrm{Rb}$ inactivation and regulates the proliferation and survival of the U87 human glioblastoma cell line. Exp Cell Res. 2007;313(4):719-31.

10. Gao Q, Zhou G, Lin SJ, Paus R, Yue Z. How chemotherapy and radiotherapy damage the tissue: comparative biology lessons from feather and hair models. Exp Dermatol. 2019;28(4):413-8.

11. Mortezaee K, Salehi E, Mirtavoos-Mahyari H, Motevaseli E, Najafi M, Farhood B, Rosengren RJ, Sahebkar A. Mechanisms of apoptosis modulation by curcumin: implications for cancer therapy. J Cell Physiol. 2019;234(8):12537-50.

12. Mortezaee K, Najafi M, Farhood B, Ahmadi A, Shabeeb D, Musa AE. Resveratrol as an adjuvant for normal tissues protection and tumor sensitization. Curr Cancer Drug Targets. 2020;20(2):130-45.

13. Mortezaee K, Shabeeb D, Musa AE, Najafi M, Farhood B. Metformin as a radiation modifier; implications to normal tissue protection and tumor sensitization. Curr Clin Pharmacol. 2019;14(1):41-53.

14. Yahyapour R, Shabeeb D, Cheki M, Musa AE, Farhood B, Rezaeyan A, et al. Radiation protection and mitigation by natural antioxidants and flavonoids: implications to radiotherapy and radiation disasters. Curr Mol Pharmacol. 2018;11(4):285-304. 
15. Gusman J, Malonne H, Atassi G. A reappraisal of the potential chemopreventive and chemotherapeutic properties of resveratrol. Carcinogenesis. 2001;22(8):1111-7.

16. Pervaiz S, Holme AL. Resveratrol: its biologic targets and functional activity. Antioxid Redox Signal. 2009;11(11):2851-97.

17. De la Lastra CA, Villegas I. Resveratrol as an antioxidant and pro-oxidant agent: mechanisms and clinical implications. Biochem Soc Trans. 2007;35(Pt 5):1156-60.

18. Koide K, Osman S, Garner AL, Song F, Dixon T, Greenberger JS, et al. The use of 3,5,4'-tri-o-acetylresveratrol as a potential pro-drug for resveratrol protects mice from $\gamma$-irradiation-induced death. ACS Med Chem Lett. 2011:2(4):270-4.

19. Bove K, Lincoln DW, Tsan MF. Effect of resveratrol on growth of 4T1 breast cancer cells in vitro and in vivo. Biochem Biophys Res Commun. 2002;291(4):1001-5

20. Walle T, Hsieh F, DeLegge MH, Oatis JE Jr, Walle UK. High absorption but very low bioavailability of oral resveratrol in humans. Drug Metab Dispos. 2004;32(12):1377-82

21. Zhong Y, Shahidi F. Lipophilized epigallocatechin gallate (EGCG) derivatives as novel antioxidants. J Agric Food Chem. 2011;59(12):6526-33.

22. Oh WY, Shahidi F. Antioxidant activity of resveratrol ester derivatives in food and biological model systems. Food Chem. 2018;261:267-73.

23. Remsberg CM, Yáñez JA, Ohgami Y, Vega-Villa KR, Rimando AM, Davies NM. Pharmacometrics of pterostilbene: preclinical pharmacokinetics and metabolism, anticancer, antiinflammatory, antioxidant and analgesic activity. Phytother Res. 2008;22(2):169-79.

24. Wang TT, Schoene NW, Kim YS, Mizuno CS, Rimando AM. Differential effects of resveratrol and its naturally occurring methylether analogs on cell cycle and apoptosis in human androgen-responsive LNCaP cancer cells. Mol Nutr Food Res. 2010;54(3):335-44.

25. Alex D, Leong EC, Zhang ZJ, Yan GT, Cheng SH, Leong CW, et al. Resveratrol derivative, trans-3,5,4'-trimethoxystilbene, exerts antiangiogenic and vascular-disrupting effects in zebrafish through the downregulation of VEGFR2 and cell-cycle modulation. J Cell Biochem. 2010;109(2):339-46

26. Horvath Z, Marihart-Fazekas S, Saiko P, Grusch M, Ozsüy M, Harik M, et al. Novel resveratrol derivatives induce apoptosis and cause cell cycle arrest in prostate cancer cell lines. Anticancer Res. 2007;27(5A):3459-64.

27. Stivala LA, Savio M, Carafoli F, Perucca P, Bianchi L, Maga G, et al. Specific structural determinants are responsible for the antioxidant activity and the cell cycle effects of resveratrol. J Biol Chem. 2001;276(25):22586-94.

28. Larrosa M, Tomás-Barberán FA, Espín JC. Grape polyphenol resveratrol and the related molecule 4-hydroxystilbene induce growth inhibition, apoptosis, S-phase arrest, and upregulation of cyclins A, E, and B1 in human SK-Mel-28 melanoma cells. J Agric Food Chem. 2003:51(16):4576-84.

29. Savio M, Coppa T, Bianchi L, Vannini V, Maga G, Forti L, et al. The resveratrol analogue 4,4'-dihydroxy-trans-stilbene inhibits cell proliferation with higher efficiency but different mechanism from resveratrol. Int J Biochem Cell Biol. 2009;41(12):2493-502.

30. Kimura Y, Sumiyoshi M, Baba K. Antitumor activities of synthetic and natural stilbenes through antiangiogenic action. Cancer Sci. 2008:99(10):2083-96.

31. Handler N, Brunhofer G, Studenik C, Leisser K, Jaeger W, Parth S, et al. 'Bridged' stilbene derivatives as selective cyclooxygenase-1 inhibitors. Bioorg Med Chem. 2007;15(18):6109-18.

32. Vergaro V, Lvov YM, Leporatti S. Halloysite clay nanotubes for resveratrol delivery to cancer cells. Macromol Biosci. 2012;12(9):1265-71.

33. Wang M, Liu Y, Zhang X, Luo L, Li L, Xing S, et al. Gold nanoshell coated thermo-pH dual responsive liposomes for resveratrol delivery and chemo-photothermal synergistic cancer therapy. J Mater Chem B. 2017:5(11):2161-71.

34. Wang W, Zhang L, Chen T, Guo W, Bao X, Wang D, et al. Anticancer effects of resveratrol-loaded solid lipid nanoparticles on human breast cancer cells. Molecules. 2017;22(11):1814.

35. Karthikeyan S, Prasad NR, Ganamani A, Balamurugan E. Anticancer activity of resveratrol-loaded gelatin nanoparticles on $\mathrm{NCl}-\mathrm{H} 460$ nonsmall cell lung cancer cells. Biomed Prev Nutr. 2013;3(1):64-73.

36. Shen B. A new golden age of natural products drug discovery. Cell. 2015:163(6):1297-300
37. Wang J, Gao L, Lee YM, Kalesh KA, Ong YS, Lim J, Jee JE, Sun H, Lee SS, Hua ZC, Lin Q. Target identification of natural and traditional medicines with quantitative chemical proteomics approaches. Pharmacol Ther. 2016;162:10-22.

38. Xiao Q, Wu J, Pang X, Jiang Y, Wang P, Leung AW, Gao L, Jiang S, Xu C. Discovery and development of natural products and their derivatives as photosensitizers for photodynamic therapy. Curr Med Chem. 2018;25(7):839-60.

39. Cragg GM, Pezzuto JM. Natural products as a vital source for the discovery of cancer chemotherapeutic and chemopreventive agents. Med Princ Pract. 2016;25(Suppl 2):41-59.

40. Sawmiller D, Li S, Shahaduzzaman M, Smith AJ, Obregon D, Giunta B, et al. Luteolin reduces Alzheimer's disease pathologies induced by traumatic brain injury. Int J Mol Sci. 2014;15(1):895-904.

41. Ishisaka A, Ichikawa S, Sakakibara H, Piskula MK, Nakamura T, Kato Y, Ito M, Miyamoto K, Tsuji A, Kawai Y, Terao J. Accumulation of orally administered quercetin in brain tissue and its antioxidative effects in rats. Free Radic Biol Med. 2011;51(7):1329-36.

42. Baur JA, Pearson KJ, Price NL, Jamieson HA, Lerin C, Kalra A, et al. Resveratrol improves health and survival of mice on a high-calorie diet. Nature. 2006;444(7117):337-42.

43. Carter LG, D'Orazio JA, Pearson KJ. Resveratrol and cancer: focus on in vivo evidence. Endocr Relat Cancer. 2014;21(3):209-25.

44. Kotecha R, Takami A, Espinoza JL. Dietary phytochemicals and cancer chemoprevention: a review of the clinical evidence. Oncotarget. 2016;7(32):52517-29.

45. Chedea VS, Vicaş SI, Sticozzi C, Pessina F, Frosini M, Maioli E, et al. Resveratrol: from diet to topical usage. Food Funct. 2017;8(11):3879-92.

46. Nawaz W, Zhou Z, Deng S, Ma X, Ma X, Li C, et al. Therapeutic versatility of resveratrol derivatives. Nutrients. 2017;9(11):1188.

47. Frémont L. Biological effects of resveratrol. Life Sci. 2000;66(8):663-73.

48. Jang M, Cai L, Udeani GO, Slowing KV, Thomas CF, Beecher CW, et al. Cancer chemopreventive activity of resveratrol, a natural product derived from grapes. Science. 1997;275(5297):218-20.

49. Kisková T, Kassayová M. Resveratrol action on lipid metabolism in cancer. Int J Mol Sci. 2019;20(11):2704.

50. Honari M, Shafabakhsh R, Reiter RJ, Mirzaei H, Asemi Z. Resveratrol is a promising agent for colorectal cancer prevention and treatment: focus on molecular mechanisms. Cancer Cell Int. 2019;19:180.

51. Ko JH, Sethi G, Um JY, Shanmugam MK, Arfuso F, Kumar AP, et al. The role of resveratrol in cancer therapy. Int J Mol Sci. 2017;18(12):2589.

52. Xiao Q, Zhu W, Feng W, Lee SS, Leung AW, Shen J, et al. A review of resveratrol as a potent chemoprotective and synergistic agent in cancer chemotherapy. Front Pharmacol. 2019;9:1534.

53. Wang Q, Xu J, Rottinghaus GE, Simonyi A, Lubahn D, Sun GY, et al. Resveratrol protects against global cerebral ischemic injury in gerbils. Brain Res. 2002;958(2):439-47.

54. Gomes BAQ, Silva JPB, Romeiro CFR, Dos Santos SM, Rodrigues CA, Gonçalves PR, et al. Neuroprotective mechanisms of resveratrol in Alzheimer's disease: role of SIRT1. Oxid Med Cell Longev. 2018;2018:8152373.

55. Martin I. Resveratrol for Alzheimer's disease? Sci Transl Med. 2017:9(375):eaam6055.

56. Sawda C, Moussa C, Turner RS. Resveratrol for Alzheimer's disease. Ann NY Acad Sci. 2017;1403(1):142-9.

57. Ferretta A, Gaballo A, Tanzarella P, Piccoli C, Capitanio N, Nico B, et al. Effect of resveratrol on mitochondrial function: implications in parkin-associated familiar Parkinson's disease. Biochim Biophys Acta. 2014;1842(7):902-15.

58. Xia D, Sui R, Zhang Z. Administration of resveratrol improved Parkinson's disease-like phenotype by suppressing apoptosis of neurons via modulating the MALAT1/miR-129/SNCA signaling pathway. J Cell Biochem. 2019;120(4):4942-51.

59. Clark PA, Bhattacharya S, Elmayan A, Darjatmoko SR, Thuro BA, Yan MB, et al. Resveratrol targeting of AKT and p53 in glioblastoma and glioblastoma stem-like cells to suppress growth and infiltration. J Neurosurg. 2017;126(5):1448-60.

60. Shu XH, Wang LL, Li H, Song X, Shi S, Gu JY, et al. Diffusion efficiency and bioavailability of resveratrol administered to rat brain by different routes: therapeutic implications. Neurotherapeutics. 2015:12(2):491-501. 
61. Burton E, Yusuf M, Gilbert MR, Gaskins J, Woo S. Failure to complete standard radiation therapy in glioblastoma patients: patterns from a national database with implications for survival and therapeutic decision making in older glioblastoma patients. J Geriatr Oncol. 2020;11(4):680-7.

62. Kirkpatrick JP, Laack NN, Shih HA, Gondi V. Management of GBM: a problem of local recurrence. J Neurooncol. 2017;134(3):487-93.

63. Fang Y, DeMarco VG, Nicholl MB. Resveratrol enhances radiation sensitivity in prostate cancer by inhibiting cell proliferation and promoting cell senescence and apoptosis. Cancer Sci. 2012;103(6):1090-8.

64. Fang Y, Bradley MJ, Cook KM, Herrick EJ, Nicholl MB. A potential role for resveratrol as a radiation sensitizer for melanoma treatment. J Surg Res. 2013;183(2):645-53.

65. Bowman T, Garcia R, Turkson J, Jove R. STATs in oncogenesis. Oncogene. 2000;19(21):2474-88.

66. Bromberg JF. Activation of STAT proteins and growth control. Bioessays. 2001;23(2):161-9.

67. Bromberg J. Stat proteins and oncogenesis. J Clin Invest. 2002;109(9):1139-42.

68. Epling-Burnette PK, Liu JH, Catlett-Falcone R, Turkson J, Oshiro M, Kothapalli R, et al. Inhibition of STAT3 signaling leads to apoptosis of leukemic large granular lymphocytes and decreased Mcl-1 expression. J Clin Invest. 2001;107(3):351-62.

69. Yu H, Jove R. The STATs of cancer-new molecular targets come of age. Nat Rev Cancer. 2004:4(2):97-105.

70. Yang YP, Chang YL, Huang PI, Chiou GY, Tseng LM, Chiou SH, et al. Resveratrol suppresses tumorigenicity and enhances radiosensitivity in primary glioblastoma tumor initiating cells by inhibiting the STAT3 axis. J Cell Physiol. 2012;227(3):976-93.

71. Lee JT, Herlyn M. Old disease, new culprit: tumor stem cells in cancer. J Cell Physiol. 2007:213(3):603-9.

72. Altaner C. Glioblastoma and stem cells. Neoplasma. 2008;55(5):369-74.

73. Hide T, Takezaki T, Nakamura H, Kuratsu J, Kondo T. Brain tumor stem cells as research and treatment targets. Brain Tumor Pathol. 2008:25(2):67-72.

74. Knizetova P, Darling JL, Bartek J. Vascular endothelial growth factor in astroglioma stem cell biology and response to therapy. J Cell Mol Med. 2008;12(1):111-25.

75. Zou GM. Cancer initiating cells or cancer stem cells in the gastrointestinal tract and liver. J Cell Physiol. 2008;217(3):598-604.

76. Bao S, Wu Q, McLendon RE, Hao Y, Shi Q, Hjelmeland AB, et al. Glioma stem cells promote radioresistance by preferential activation of the DNA damage response. Nature. 2006;444(7120):756-60.

77. Nguyen HG, Ravid K. Tetraploidy/aneuploidy and stem cells in cancer promotion: the role of chromosome passenger proteins. J Cell Physiol. 2006;208(1):12-22.

78. Chiou SH, Kao CL, Chen YW, Chien CS, Hung SC, Lo JF, et al. Identification of CD133-positive radioresistant cells in atypical teratoid/rhabdoid tumor. PLoS ONE. 2008:3(5):e2090.

79. Kao CL, Huang PI, Tsai PH, Tsai ML, Lo JF, Lee YY, et al. Resveratrolinduced apoptosis and increased radiosensitivity in CD133-positive cells derived from atypical teratoid/rhabdoid tumor. Int J Radiat Oncol Biol Phys. 2009;74(1):219-28.

80. Trosko JE, Chang CC. Mechanism of up-regulated gap junctional intercellular communication during chemoprevention and chemotherapy of cancer. Mutat Res. 2001;480-481:219-29.

81. Yamasaki H, Hollstein M, Mesnil M, Martel N, Aguelon AM. Selective lack of intercellular communication between transformed and nontransformed cells as a common property of chemical and oncogene transformation of BALB/c 3T3 cells. Cancer Res. 1987:47(21):5658-64.

82. Leone S, Fiore M, Lauro MG, Pino S, Cornetta T, Cozzi R. Resveratrol and $X$ rays affect gap junction intercellular communications in human glioblastoma cells. Mol Carcinog. 2008;47(8):587-98.

83. Najafi M, Farhood B, Mortezaee K, Kharazinejad E, Majidpoor J, Ahadi R. Hypoxia in solid tumors: a key promoter of cancer stem cell (CSC) resistance. J Cancer Res Clin Oncol. 2020;146(1):19-31.

84. Rankin EB, Giaccia AJ. Hypoxic control of metastasis. Science. 2016;352(6282):175-80

85. Chouaib S, Noman MZ, Kosmatopoulos K, Curran MA. Hypoxic stress: obstacles and opportunities for innovative immunotherapy of cancer. Oncogene. 2017;36(4):439-45.
86. Wu SL, Li YJ, Liao K, Shi L, Zhang N, Liu S, et al. 2-Methoxyestradiol inhibits the proliferation and migration and reduces the radioresistance of nasopharyngeal carcinoma CNE-2 stem cells via NF-KB/HIF-1 signaling pathway inactivation and EMT reversal. Oncol Rep. 2017;37(2):793-802.

87. Li Z, Bao S, Wu Q, Wang H, Eyler C, Sathornsumetee S, et al. Hypoxiainducible factors regulate tumorigenic capacity of glioma stem cells. Cancer Cell. 2009;15(6):501-13.

88. Schwab LP, Peacock DL, Majumdar D, Ingels JF, Jensen LC, Smith KD, et al. Hypoxia-inducible factor 1 a promotes primary tumor growth and tumor-initiating cell activity in breast cancer. Breast Cancer Res. 2012;14(1):R6

89. Van den Beucken T, Koch E, Chu K, Rupaimoole R, Prickaerts P, Adriaens $M$, et al. Hypoxia promotes stem cell phenotypes and poor prognosis through epigenetic regulation of DICER. Nat Commun. 2014;5:5203.

90. Carnero A, Lleonart M. The hypoxic microenvironment: a determinant of cancer stem cell evolution. Bioessays. 2016;38(Suppl 1):65-74.

91. Qin J, Liu Y, Lu Y, Liu M, Li M, Li J, et al. Hypoxia-inducible factor 1 alpha promotes cancer stem cells-like properties in human ovarian cancer cells by upregulating SIRT1 expression. Sci Rep. 2017;7(1):10592.

92. Jeong H, Kim S, Hong BJ, Lee CJ, Kim YE, Bok S, et al. Tumor-associated macrophages enhance tumor hypoxia and aerobic glycolysis. Cancer Res. 2019;79(4):795-806.

93. Kao SH, Cheng WC, Wang YT, Wu HT, Yeh HY, Chen YJ, et al. Regulation of miRNA biogenesis and histone modification by K63-polyubiquitinated DDX17 controls cancer stem-like features. Cancer Res. 2019;79(10):2549-63.

94. Vadde R, Vemula S, Jinka R, Merchant N, Bramhachari PV, Nagaraju GP. Role of hypoxia-inducible factors (HIF) in the maintenance of stemness and malignancy of colorectal cancer. Crit Rev Oncol Hematol. 2017;113:22-7.

95. Iyer AK, Singh A, Ganta S, Amiji MM. Role of integrated cancer nanomedicine in overcoming drug resistance. Adv Drug Deliv Rev. 2013;65(13-14):1784-802

96. Spirou SV, Basini M, Lascialfari A, Sangregorio C, Innocenti C. Magnetic hyperthermia and radiation therapy: radiobiological principles and current practice. Nanomaterials (Basel). 2018;8(6):401.

97. Eckert F, Zwirner K, Boeke S, Thorwarth D, Zips D, Huber SM. Rationale for combining radiotherapy and immune checkpoint inhibition for patients with hypoxic tumors. Front Immunol. 2019;10:407.

98. Sharma GM. Hypoxia inducible factor-1a (HIF-1 a) and its role in tumour progression to malignancy. Online J Health Allied Sci. 2008;7(2):6.

99. Baur JA, Sinclair DA. Therapeutic potential of resveratrol: the in vivo evidence. Nat Rev Drug Discov. 2006;5(6):493-506.

100. Khoei S, Shoja M, Mostaar A, Faeghi F. Effects of resveratrol and methoxyamine on the radiosensitivity of iododeoxyuridine in U87MG glioblastoma cell line. Exp Biol Med (Maywood). 2016;241(11):1229-36.

101. Wang $L$, Long $L$, Wang $W$, Liang Z . Resveratrol, a potential radiation sensitizer for glioma stem cells both in vitro and in vivo. J Pharmacol Sci. 2015;129(4):216-25

102. Luo H, Wang L, Schulte BA, Yang A, Tang S, Wang GY. Resveratrol enhances ionizing radiation-induced premature senescence in lung cancer cells. Int J Oncol. 2013;43(6):1999-2006.

103. Xin H, Kong Y, Jiang X, Wang K, Qin X, Miao ZH, et al. Multi-drugresistant cells enriched from chronic myeloid leukemia cells by doxorubicin possess tumor-initiating-cell properties. J Pharmacol Sci. 2013;122(4):299-304.

104. Semenza GL. The hypoxic tumor microenvironment: a driving force for breast cancer progression. Biochim Biophys Acta. 2016;1863(3):382-91.

105. Olivier C, Oliver $L$, Lalier $L$, Vallette FM. Drug resistance in glioblastoma: the two faces of oxidative stress. Front Mol Biosci. 2021;7:620677.

106. Jia B, Zheng X, Wu ML, Tian XT, Song X, Liu YN, et al. Increased reactive oxygen species and distinct oxidative damage in resveratrol-suppressed glioblastoma cells. J Cancer. 2021;12(1):141-9.

107. Santandreu FM, Valle A, Oliver J, Roca P. Resveratrol potentiates the cytotoxic oxidative stress induced by chemotherapy in human colon cancer cells. Cell Physiol Biochem. 2011;28(2):219-28.

108. Öztürk Y, Günaydın C, Yalçın F, Nazıroğlu M, Braidy N. Resveratrol enhances apoptotic and oxidant effects of paclitaxel through TRPM2 channel activation in DBTRG glioblastoma cells. Oxid Med Cell Longev. 2019;2019:4619865. 
109. Nejati K, Alivand M, Arabzadeh A. MicroRNA-22 in female malignancies: focusing on breast, cervical, and ovarian cancers. Pathol Res Pract. 2021;223:153452.

110. Krakstad C, Chekenya M. Survival signalling and apoptosis resistance in glioblastomas: opportunities for targeted therapeutics. Mol Cancer. 2010;9:135.

111. Lin HY, Tang HY, Keating T, Wu YH, Shih A, Hammond D, et al. Resveratrol is pro-apoptotic and thyroid hormone is anti-apoptotic in glioma cells: both actions are integrin and ERK mediated. Carcinogenesis. 2008;29(1):62-9.

112. Lin HY, Shih A, Davis FB, Tang HY, Martino LJ, Bennett JA, et al. Resveratrol induced serine phosphorylation of p53 causes apoptosis in a mutant p53 prostate cancer cell line. J Urol. 2002;168(2):748-55.

113. Zhang S, Cao HJ, Davis FB, Tang HY, Davis PJ, Lin HY. Oestrogen inhibits resveratrol-induced post-translational modification of p53 and apoptosis in breast cancer cells. Br J Cancer. 2004;91(1):178-85.

114. Lin HY, Sun M, Tang HY, Simone TM, Wu YH, Grandis JR, et al. Resveratrol causes COX-2- and p53-dependent apoptosis in head and neck squamous cell cancer cells. J Cell Biochem. 2008;104(6):2131-42.

115. Liu Y, Tong L, Luo Y, Li X, Chen G, Wang Y. Resveratrol inhibits the proliferation and induces the apoptosis in ovarian cancer cells via inhibiting glycolysis and targeting AMPK/mTOR signaling pathway. J Cell Biochem. 2018;119(7):6162-72.

116. Wang G, Dai F, Yu K, Jia Z, Zhang A, Huang Q, et al. Resveratrol inhibits glioma cell growth via targeting oncogenic microRNAs and multiple signaling pathways. Int J Oncol. 2015;46(4):1739-47.

117. Dörrie J, Gerauer H, Wachter Y, Zunino SJ. Resveratrol induces extensive apoptosis by depolarizing mitochondrial membranes and activating caspase-9 in acute lymphoblastic leukemia cells. Cancer Res. 2001;61(12):4731-9.

118. Lin H, Xiong W, Zhang X, Liu B, Zhang W, Zhang Y, et al. Notch-1 activation-dependent p53 restoration contributes to resveratrol-induced apoptosis in glioblastoma cells. Oncol Rep. 2011;26(4):925-30.

119. Li H, Liu Y, Jiao Y, Guo A, Xu X, Qu X, et al. Resveratrol sensitizes glioblastoma-initiating cells to temozolomide by inducing cell apoptosis and promoting differentiation. Oncol Rep. 2016;35(1):343-51.

120. Huang $\mathrm{H}$, Lin H, Zhang $X$, Li J. Resveratrol reverses temozolomide resistance by downregulation of MGMT in T98G glioblastoma cells by the NF-kB-dependent pathway. Oncol Rep. 2012;27(6):2050-6.

121. Yang HC, Wang JY, Bu XY, Yang B, Wang BQ, Hu S, et al. Resveratrol restores sensitivity of glioma cells to temozolamide through inhibiting the activation of Wnt signaling pathway. J Cell Physiol. 2019;234(5):6783-800.

122. Liu Y, Song X, Wu M, Wu J, Liu J. Synergistic effects of resveratrol and temozolomide against glioblastoma cells: underlying mechanism and therapeutic implications. Cancer Manag Res. 2020;12:8341-54.

123. Ding $X Z$, Adrian TE. Resveratrol inhibits proliferation and induces apoptosis in human pancreatic cancer cells. Pancreas. 2002;25(4):71-6.

124. Chin YT, Hsieh MT, Yang SH, Tsai PW, Wang SH, Wang CC, et al. Antiproliferative and gene expression actions of resveratrol in breast cancer cells in vitro. Oncotarget. 2014;5(24):12891-907.

125. Lei MJ, Dong Y, Sun CX, Zhang XH. Resveratrol inhibits proliferation, promotes differentiation and melanogenesis in HT-144 melanoma cells through inhibition of MEK/ERK kinase pathway. Microb Pathog. 2017:111:410-3.

126. Li X, Wang D, Zhao QC, Shi T, Chen J. Resveratrol inhibited non-small cell lung cancer through inhibiting STAT-3 signaling. Am J Med Sci. 2016;352(5):524-30

127. Subbaramaiah K, Chung WJ, Michaluart P, Telang N, Tanabe T, Inoue H, et al. Resveratrol inhibits cyclooxygenase-2 transcription and activity in phorbol ester-treated human mammary epithelial cells. J Biol Chem. 1998;273(34):21875-82.

128. Fulda S. Resveratrol and derivatives for the prevention and treatment of cancer. Drug Discov Today. 2010;15(17-18):757-65.

129. Rashid A, Liu C, Sanli T, Tsiani E, Singh G, Bristow RG, et al. Resveratrol enhances prostate cancer cell response to ionizing radiation. Modulation of the AMPK, Akt and mTOR pathways. Radiat Oncol. 2011;6:144.

130. Fiore M, Festa F, Cornetta T, Ricordy R, Cozzi R. Resveratrol affects X-ray induced apoptosis and cell cycle delay in human cells in vitro. Int J Mol Med. 2005;15(6):1005-12.
131. Zoberi I, Bradbury CM, Curry HA, Bisht KS, Goswami PC, Roti Roti JL, et al. Radiosensitizing and anti-proliferative effects of resveratrol in two human cervical tumor cell lines. Cancer Lett. 2002;175(2):165-73.

132. Yang Q, Wang B, Zang W, Wang X, Liu Z, Li W, et al. Resveratrol inhibits the growth of gastric cancer by inducing G1 phase arrest and senescence in a Sirt1-dependent manner. PLOS ONE. 2013;8(11):e70627.

133. Yuan $Y, X u e X$, Guo RB, Sun XL, Hu G. Resveratrol enhances the antitumor effects of temozolomide in glioblastoma via ROSdependent AMPK-TSC-mTOR signaling pathway. CNS Neurosci Ther. 2012;18(7):536-46.

134. Najafi M, Farhood B, Mortezaee K. Cancer stem cells (CSCs) in cancer progression and therapy. J Cell Physiol. 2019;234(6):8381-95.

135. Clayton SM, Archard JA, Wagner J, Farwell DG, Bewley AF, Beliveau A, et al. Immunoregulatory potential of exosomes derived from cancer stem cells. Stem Cells Dev. 2020;29(6):327-35.

136. Yu Z, Pestell TG, Lisanti MP, Pestell RG. Cancer stem cells. Int J Biochem Cell Biol. 2012;44(12):2144-51.

137. Diehn M, Clarke MF. Cancer stem cells and radiotherapy: new insights into tumor radioresistance. J Natl Cancer Inst. 2006;98(24):1755-7.

138. Chen J, Li Y, Yu TS, McKay RM, Burns DK, Kernie SG, et al. A restricted cell population propagates glioblastoma growth after chemotherapy. Nature. 2012:488(7412):522-6.

139. Thirant C, Bessette B, Varlet P, Puget S, Cadusseau J, Tavares Sdos R, et al. Clinical relevance of tumor cells with stem-like properties in pediatric brain tumors. PLoS ONE. 2011;6(1):e16375.

140. Eyler CE, Rich JN. Survival of the fittest: cancer stem cells in therapeutic resistance and angiogenesis. J Clin Oncol. 2008;26(17):2839-45.

141. Singh SK, Clarke ID, Terasaki M, Bonn VE, Hawkins C, Squire J, et al. Identification of a cancer stem cell in human brain tumors. Cancer Res. 2003;63(18):5821-8.

142. Pollard SM, Yoshikawa K, Clarke ID, Danovi D, Stricker S, Russell R, et al. Glioma stem cell lines expanded in adherent culture have tumorspecific phenotypes and are suitable for chemical and genetic screens. Cell Stem Cell. 2009;4(6):568-80.

143. Dirks PB. Brain tumor stem cells: the cancer stem cell hypothesis writ large. Mol Oncol. 2010;4(5):420-30.

144. Bjerkvig R, Tysnes BB, Aboody KS, Najbauer J, Terzis AJ. Opinion: the origin of the cancer stem cell: current controversies and new insights. Nat Rev Cancer. 2005;5(11):899-904.

145. Ehtesham M, Mapara KY, Stevenson CB, Thompson RC. CXCR4 mediates the proliferation of glioblastoma progenitor cells. Cancer Lett. 2009;274(2):305-12.

146. Persano L, Rampazzo E, Basso G, Viola G. Glioblastoma cancer stem cells: role of the microenvironment and therapeutic targeting. Biochem Pharmacol. 2013;85(5):612-22.

147. Soehngen E, Schaefer A, Koeritzer J, Huelsmeyer V, Zimmer C, Ringel F, et al. Hypoxia upregulates aldehyde dehydrogenase isoform 1 (ALDH1) expression and induces functional stem cell characteristics in human glioblastoma cells. Brain Tumor Pathol. 2014;31(4):247-56.

148. Ma J, Yao Y, Wang P, Liu Y, Zhao L, Li Z, et al. MiR-152 functions as a tumor suppressor in glioblastoma stem cells by targeting Krüppel-like factor 4. Cancer Lett. 2014;355(1):85-95.

149. Zhang L, Yan Y, Jiang Y, Cui Y, Zou Y, Qian J, et al. The expression of SALL4 in patients with gliomas: high level of SALL4 expression is correlated with poor outcome. J Neurooncol. 2015;121(2):261-8.

150. Di Tomaso T, Mazzoleni S, Wang E, Sovena G, Clavenna D, Franzin A, et al. Immunobiological characterization of cancer stem cells isolated from glioblastoma patients. Clin Cancer Res. 2010;16(3):800-13.

151. Jung CS, Foerch C, Schänzer A, Heck A, Plate KH, Seifert V, et al. Serum GFAP is a diagnostic marker for glioblastoma multiforme. Brain. 2007;130(Pt 12):3336-41.

152. Bradshaw A, Wickremsekera A, Tan ST, Peng L, Davis PF, Itinteang T. Cancer stem cell hierarchy in glioblastoma multiforme. Front Surg. 2016:3:21.

153. Alves ALV, Gomes INF, Carloni AC, Rosa MN, da Silva LS, Evangelista AF, et al. Role of glioblastoma stem cells in cancer therapeutic resistance: a perspective on antineoplastic agents from natural sources and chemical derivatives. Stem Cell Res Ther. 2021;12(1):206.

154. Song Y, Chen Y, Li Y, Lyu X, Cui J, Cheng Y, et al. Resveratrol suppresses epithelial-mesenchymal transition in GBM by regulating Smad-dependent signaling. Biomed Res Int. 2019;2019:1321973. 
155. Sayd S, Thirant C, El-Habr EA, Lipecka J, Dubois LG, Bogeas A, et al. Sirtuin-2 activity is required for glioma stem cell proliferation arrest but not necrosis induced by resveratrol. Stem Cell Rev Rep. 2014;10(1):103-13.

156. Cilibrasi C, Riva G, Romano G, Cadamuro M, Bazzoni R, Butta V, et al. Resveratrol impairs glioma stem cells proliferation and motility by modulating the Wnt signaling pathway. PLoS ONE. 2017;12(1):e0169854.

157. Tsuchihara K, Fujii S, Esumi H. Autophagy and cancer: dynamism of the metabolism of tumor cells and tissues. Cancer Lett. 2009:278(2):130-8.

158. Trincheri NF, Nicotra G, Follo C, Castino R, Isidoro C. Resveratrol induces cell death in colorectal cancer cells by a novel pathway involving lysosomal cathepsin D. Carcinogenesis. 2007;28(5):922-31.

159. Park D, Jeong H, Lee MN, Koh A, Kwon O, Yang YR, et al. Resveratrol induces autophagy by directly inhibiting mTOR through ATP competition. Sci Rep. 2016;6:21772.

160. Tian Y, Song W, Li D, Cai L, Zhao Y. Resveratrol as a natural regulator of autophagy for prevention and treatment of cancer. Onco Targets Ther. 2019;17:8601-9.

161. Zhao F, Huang W, Zhang Z, Mao L, Han Y, Yan J, et al. Triptolide induces protective autophagy through activation of the CaMKKß-AMPK signaling pathway in prostate cancer cells. Oncotarget. 2016;7(5):5366-82.

162. Lefranc F, Facchini V, Kiss R. Proautophagic drugs: a novel means to combat apoptosis-resistant cancers, with a special emphasis on glioblastomas. Oncologist. 2007;12(12):1395-403.

163. Filippi-Chiela EC, Thomé MP, Bueno e Silva MM, Pelegrini AL, Ledur PF, Garicochea B, Zamin LL, Lenz G. Resveratrol abrogates the temozolomide-induced $\mathrm{G} 2$ arrest leading to mitotic catastrophe and reinforces the temozolomide-induced senescence in glioma cells. BMC Cancer. 2013;13:147.

164. Zanotto-Filho A, Braganhol E, Klafke K, Figueiró F, Terra SR, Paludo $\mathrm{FJ}$, et al. Autophagy inhibition improves the efficacy of curcumin/ temozolomide combination therapy in glioblastomas. Cancer Lett. 2015;358(2):220-31.

165. Sirichanchuen B, Pengsuparp T, Chanvorachote P. Long-term cisplatin exposure impairs autophagy and causes cisplatin resistance in human lung cancer cells. Mol Cell Biochem. 2012;364(1-2):11-8.

166. Sengupta S, Chowdhury S, Bosedasgupta S, Wright CW, Majumder HK. Cryptolepine-induced cell death of Leishmania donovani promastigotes is augmented by inhibition of autophagy. Mol Biol Int. 2011;2011:187850.

167. Filippi-Chiela EC, Villodre ES, Zamin LL, Lenz G. Autophagy interplay with apoptosis and cell cycle regulation in the growth inhibiting effect of resveratrol in glioma cells. PLoS ONE. 2011;6(6):e20849.

168. Li J, Qin Z, Liang Z. The prosurvival role of autophagy in resveratrolinduced cytotoxicity in human U251 glioma cells. BMC Cancer. 2009:9:215.

169. Xue S, Xiao-Hong S, Lin S, Jie B, Li-Li W, Jia-Yao G, et al. Lumbar puncture-administered resveratrol inhibits STAT3 activation, enhancing autophagy and apoptosis in orthotopic rat glioblastomas. Oncotarget. 2016;7(46):75790-9

170. Wang J, Li J, Cao N, Li Z, Han J, Li L. Resveratrol, an activator of SIRT1, induces protective autophagy in non-small-cell lung cancer via inhibiting Akt/mTOR and activating p38-MAPK. Onco Targets Ther. 2018;11:7777-86.

171. Fan Y, Chiu JF, Liu J, Deng Y, Xu C, Zhang J, et al. Resveratrol induces autophagy-dependent apoptosis in HL-60 cells. BMC Cancer. 2018;18(1):581.

172. Lin CJ, Lee CC, Shih YL, Lin TY, Wang SH, Lin YF, et al. Resveratrol enhances the therapeutic effect of temozolomide against malignant glioma in vitro and in vivo by inhibiting autophagy. Free Radic Biol Med. 2012;52(2):377-91.
173. Siddiqui A, Dandawate P, Rub R, Padhye S, Aphale S, Moghe A, et al. Novel Aza-resveratrol analogs: synthesis, characterization and anticancer activity against breast cancer cell lines. Bioorg Med Chem Lett. 2013;23(3):635-40.

174. Mikuła-Pietrasik J, Sosińska P, Murias M, Wierzchowski M, BrewińskaOlchowik M, Piwocka K, et al. High potency of a novel resveratrol derivative, 3,3'4,4'-tetrahydroxy-trans-stilbene, against ovarian cancer is associated with an oxidative stress-mediated imbalance between DNA damage accumulation and repair. Oxid Med Cell Longev. 2015;2015:135691.

175. Zheng X, Yu L, Yao X, Lv B, Yang Z, Zheng Q, et al. Synthesis and anti-cancer activities of resveratrol derivatives. Open J Med Chem. 2016;6(03):51-7.

176. Parida PK, Mahata B, Santra A, Chakraborty S, Ghosh Z, Raha S, et al. Inhibition of cancer progression by a novel trans-stilbene derivative through disruption of microtubule dynamics, driving G2/M arrest, and p53-dependent apoptosis. Cell Death Dis. 2018;9(5):448.

177. Chelsky ZL, Yue P, Kondratyuk TP, Paladino D, Pezzuto JM, Cushman $\mathrm{M}$, et al. A resveratrol analogue promotes ERKMAPK-dependent Stat3 serine and tyrosine phosphorylation alterations and antitumor effects in vitro against human tumor cells. Mol Pharmacol. 2015;88(3):524-33.

178. Ahmadi R, Ebrahimzadeh MA. Resveratrol-a comprehensive review of recent advances in anticancer drug design and development. Eur J Med Chem. 2020;200:112356.

179. Zielińska-Przyjemska M, Kaczmarek M, Krajka-Kuźniak V, Łuczak M, BaerDubowska W. The effect of resveratrol, its naturally occurring derivatives and tannic acid on the induction of cell cycle arrest and apoptosis in rat C6 and human T98G glioma cell lines. Toxicol In Vitro. 2017;43:69-75.

180. Majchrzak-Celińska A, Zielińska-Przyjemska M, Wierzchowski M, Kleszcz R, Studzińska-Sroka E, Kaczmarek M, et al. Methoxy-stilbenes downregulate the transcription of Wnt/ $\beta$-catenin-dependent genes and lead to cell cycle arrest and apoptosis in human T98G glioblastoma cells. Adv Med Sci. 2021;66(1):6-20.

181. Ahmadi Z, Mohammadinejad R, Ashrafizadeh M. Drug delivery systems for resveratrol, a non-flavonoid polyphenol: emerging evidence in last decades. J Drug Deliv Sci Technol. 2019;51:591-604.

182. Shao J, Li X, Lu X, Jiang C, Hu Y, Li Q, et al. Enhanced growth inhibition effect of resveratrol incorporated into biodegradable nanoparticles against glioma cells is mediated by the induction of intracellular reactive oxygen species levels. Colloids Surf B Biointerfaces. 2009;72(1):40-7.

183. Figueiró F, Bernardi A, Frozza RL, Terroso T, Zanotto-Filho A, Jandrey EH, et al. Resveratrol-loaded lipid-core nanocapsules treatment reduces in vitro and in vivo glioma growth. J Biomed Nanotechnol. 2013;9(3):516-26.

184. Guo W, Li A, Jia Z, Yuan Y, Dai H, Li H. Transferrin modified PEG-PLAresveratrol conjugates: in vitro and in vivo studies for glioma. Eur J Pharmacol. 2013;718(1-3):41-7.

185. Jhaveri A, Deshpande P, Pattni B, Torchilin V. Transferrin-targeted, resveratrol-loaded liposomes for the treatment of glioblastoma. J Control Release. 2018;277:89-101.

186. Xu H, Jia F, Singh PK, Ruan S, Zhang H, Li X. Synergistic anti-glioma effect of a coloaded nano-drug delivery system. Int I Nanomed. 2016:12:29-40.

\section{Publisher's Note}

Springer Nature remains neutral with regard to jurisdictional claims in published maps and institutional affiliations. 